\title{
Clinical analysis and predictive factors associated with improved visual acuity of infectious endophthalmitis
}

\author{
Zhao Gao ${ }^{1,2}$, Yunda Zhang ${ }^{2}$, Xiaohong Gao ${ }^{2}$, Ximei Zhang ${ }^{2}$, Tao Ma², Gaiyun Li², Jingjing Wang ${ }^{3}$ and Hua Yan ${ }^{1 *}$ (D
}

\begin{abstract}
Background: To describe the clinical characteristics and analyze the predictive factors associated with improved visual acuity of 359 patients with infectious endophthalmitis.

Methods: This study retrospectively analyzed 359 eyes of 359 patients with infectious endophthalmitis from January 2014 to December 2018. The findings summarized some epidemiological characteristics of these patients, including age, sex, occupation, patient visit time, etiology, causative organisms, therapy, and best-corrected visual acuity. Multivariate logistic regression was performed to predict the relative factors of improved visual acuity (VA).

Results: Overall, 283 (78.83\%) patients were male. The mean age was $48.0 \pm 18.27$ years. Ocular trauma, especially open globe injuries $(246,68.5 \%)$ was the most common etiology of infectious endophthalmitis in this study. The etiologies of infectious endophthalmitis were open globe injuries (68.5\%), intraocular surgery (22.6\%), and corneal ulcer-associated (6.7\%) and endogenous causes (2.2\%). In the etiology classification and visual acuity improvement group, had statistically significant differences in factors such as age, sex, patient visit time, pre-therapy visual acuity, etc. The average Logarithm of the Minimum Angle of Resolution (logMAR) best-corrected visual acuity on pretherapy was $2.28 \pm 0.60$, and it had significantly improved to $1.67 \pm 0.83$ post-therapy $(P<0.05)$. Logistic regression analysis showed that visit time $>7$ day $(P=0.034, \mathrm{OR}=0.522,95 \% \mathrm{Cl}: 0.286-0.953)$, pre-therapy VA $\leqq$ logMAR $2.3(P=$ 0.032, $\mathrm{OR}=1.809,95 \% \mathrm{Cl}: 1.052-3.110$ ), post-surgical (vs. posttraumatic; $P=0.023, \mathrm{OR}=2.100,95 \% \mathrm{Cl}: 1.109-3.974$ ), and corneal ulcer-associated etiologies (vs. posttraumatic; $P=0.005, \mathrm{OR}=0.202,95 \% \mathrm{Cl}$ : 0.066-0.621) were significantly associated with improved visual acuity after adjusting for possible confounding factors.

Conclusions: Among the patients with infectious endophthalmitis, middle-aged male, especially farmers and workers, accounted for a large proportion. Open globe injuries were the main cause and the gram-positive bacteria were the major causative organisms. The final visual outcomes seemed to vary according to the type of endophthalmitis, but early treatment and good initial visual acuity were important factors for visual acuity improvement.
\end{abstract}

Keywords: Endophthalmitis, Clinical characteristics, Causative organisms, Visual acuity, Predictive factors

\footnotetext{
*Correspondence: phuayan2000@163.com

'Department of Ophthalmfology, Tianjin Medical University General Hospital,

No. 154, Anshan Road, Tianjin 300052, China

Full list of author information is available at the end of the article
}

\section{$\triangle B M C$}

(c) The Author(s). 2020 Open Access This article is licensed under a Creative Commons Attribution 4.0 International License, which permits use, sharing, adaptation, distribution and reproduction in any medium or format, as long as you give appropriate credit to the original author(s) and the source, provide a link to the Creative Commons licence, and indicate if changes were made. The images or other third party material in this article are included in the article's Creative Commons licence, unless indicated otherwise in a credit line to the material. If material is not included in the article's Creative Commons licence and your intended use is not permitted by statutory regulation or exceeds the permitted use, you will need to obtain permission directly from the copyright holder. To view a copy of this licence, visit http://creativecommons.org/licenses/by/4.0/ The Creative Commons Public Domain Dedication waiver (http://creativecommons.org/publicdomain/zero/1.0/) applies to the data made available in this article, unless otherwise stated in a credit line to the data. 


\section{Background}

Endophthalmitis is a severe inflammation of intraocular fluids usually caused by the infection of contaminating microorganisms following trauma, surgery, or hematogenous spread from the distant infection parts. Because of the difficulty in diagnosis and the low bacterial culture positivity rate, the detection and treatment of this disease are primarily based on the physician's clinical experience [1-3]. Although the prognosis of endophthalmitis has shown enormous progress in the cases of endophthalmitis due to the use of effective intraocular antibiotics and the advances in vitreoretinal surgery, there are still several cases of virulent infection leading to irreversible visual impairment and even the enucleation of the eye [4]. Few studies have investigated the risk factors associated with endophthalmitis and visual impairment. Durand reported that there was a reasonably high correlation between the visual outcome and pathogenic microbiology [5], Streptococci can produce severe endophthalmitis with a poor visual outcome, whereas coagulase-negative staphylococci cause milder endophthalmitis in general. Yosanan et al. found that the only possible predictive factor associated with improved visual outcomes was pars plana vitrectomy (PPV) within 3 days [6].

Endophthalmitis can be classified as exogenous and endogenous. Exogenous endophthalmitis is categorized as postsurgical, posttraumatic, or corneal ulcerassociated. In contrast, endogenous endophthalmitis is caused by blood infection or immunosuppression [7, 8]. The incidence of endophthalmitis varies according to location, economy, and ethnicity. In a German study, Lothar Kraus et al. reported that endophthalmitis following open ocular injury accounted for $12 \%$ of the examined patients with endophthalmitis, while $41 \%$ of the patients showed endogenous endophthalmitis [9]. In contrast, a western China study reported that only $7.8 \%$ of 1593 endophthalmitis cases had an endogenous origin, and up to $82.6 \%$ were posttraumatic in nature [2].

Moreover, endophthalmitis has a high incidence in middle-aged male patients [2], which could have a significant impact on the patients' family and society. Therefore, it is extremely important to thoroughly understand the epidemiological characteristics of endophthalmitis and the predictable factors associated with visual acuity (VA) improvement.

\section{Methods}

\section{Ethical approval}

This retrospective, single-center study was conducted in accordance with the tenets of the Declaration of Helsinki of the World Medical Association, and approved by the institutional review board of Shanxi Eye Hospital. The requirement for informed consent was waived due to the retrospective nature of this study.

\section{Participants}

Patients who were diagnosed with endophthalmitis between January 1, 2014, and December 31, 2018, from Shanxi eye hospital, were included in this study. The included criteria were as follows: decreased vision, red eye and pain associated with hypopyon, fibrin, severe anterior chamber reaction, vitreous inflammation hypopyon, decreased red reflex, and history of intraocular surgery or an open eye injury or systemic disease [10]. The excluded criteria were as follows: allergic uveitis of the lens cortex, sympathetic ophthalmia, toxic reaction syndrome of the anterior segment after intraocular surgery, various forms of autoimmune uveitis, and other forms of uveitis. There were 359 eyes (359 patients) were ultimately included in the final statistical analysis.

\section{Measurements}

Patient data included the time of injury (grouped by year), age $(0-15,16-30,31-45,46-60,61-75$, or $\geq 76$ years), sex (male or female), marital status (married, single, divorced, or widowed), occupation (farmer, worker, office clerk, retired, student, or others), etiology (posttraumatic, corneal ulcer-associated, endogenous and postsurgical, including post-cataract, post-glaucoma, post-PPV, post- intraocular injection (IVI)), pre-therapy and post-therapy VA, therapy modalities (medical therapy, intravitreal antibiotic injections, pars plana vitrectomy, and enucleation), and causative organisms (Gram-positive, Gram-negative, fungi, or culture negative).

VA was converted to logMAR units using an international standard visual chart. Counting fingers (CFs), hand movement (HM), light perception (LP), and no LP (NLP) were converted to 1.9, 2.3, 2.7, and 3.0 logMAR, respectively [11]. Eyes that had been enucleated were assigned a logMAR value of 3.0 (NLP) [12].

The improved VA after treatment was considered the primary indicator. The patients were classified as having "improved" VA when their best-corrected VA (BCVA) rates were better post-therapy than pre-therapy. They were classified as "not improved" when the final BCVA rates were stable or worse than the initial values [6].

We followed an endophthalmitis protocol [10, 13-15]: All patients received topical and intravenous antibiotics, including vancomycin and/or ceftazidime. Then, we adjusted the antibiotic dosage according to the results of the bacterial culture and the drug sensitivity test. (1) There are inflammatory cells(++)in the anterior chamber, but no hypopyon and vitreous opacity are found, which should be closely observed and combined with medical therapy (MT), defined as the appropriate 
topical, periocular, and systemic antibiotic administration. (2) There is hypopyon or slight opacity of the vitreous body examined by B-ultrasound, and the fundus red light reflex can be seen. Moreover patients with VA of HM (2.3 logMAR) or better, can receive intravitreal antibiotic injections (IVA) combined with MT. Patients who presented with a VA of light perception and corneal involvement precluding surgery were managed similarly. (3) Patients with VA worse than HM (2.3 logMAR) and with sufficiently clear corneal, hypopyon complicated, vitreous opacity, and disappearance of red light reflex were treated with PPV as a primary procedure, including IVA and MT. When there was an intraocular foreign body (IOFB), PPV was performed first. (4) In cases where the aforementioned treatment is not effective, the corneal ulcer perforation is serious, and the patient's vision has no light perception, enucleation should be considered.

\section{Statistical analysis}

Data were aggregated using Microsoft Excel (Microsoft Corporation, Redmond, WA, USA) and statistically analyzed using SPSS 25.0 (IBM, Corp., Armonk, NY, USA). The results of descriptive analyses were expressed as counts and percentages for categorical variables, and as means \pm standard deviations (SD) for continuous variables. Differences in the measurement data were detected by analyses using the $\mathrm{t}$ - or $\mathrm{X}^{2}$ test. Multivariate analysis to ascertain the identified variables on the likelihood of improved visual outcome was performed using binomial logistic regression. The difference was considered significant when the $P$-value was $<0.05$.

\section{Results}

The basic characteristics of patients with infectious endophthalmitis recruited in this retrospective study are shown in Fig. 1. Altogether, 359 eyes from 359 patients were diagnosed as showing infectious endophthalmitis, and the patients were treated at our hospital within 5 years. In the 5-year case count, the overall trend showed an increase, but with a small drop in 2016 and 2017 (2014: 62, 2015: 76, 2016: 73, 2017: 68, and 2018: 80).

\section{Age, sex, marital status, occupation and eye characteristics}

The average age of the injured patients was $48.0 \pm 18.27$ years (range, 4 to 86 years), and the median age was 48 years. The 46-60-year $(108,30.1 \%)$ and 31-45-year $(92$, $25.6 \%)$ age groups contained the most cases. Of the 359 patients, 283 were male $(78.8 \%)$ and 76 were female (21.2\%). The male-to-female ratio was 3.7:1. In the injured population, $77.4 \%$ (278) of the patients were married, $15.6 \%$ (56) were single, $2.5 \%$ (9) were divorced, and $4.5 \%$ (16) were widowed. The patients were mainly involved in five kinds of occupations: farmers, workers, students, retired, office clerks, and others, with the corresponding incidence rates being 39.3, 32.9, 6.1, 6.1, 4.2, and $11.4 \%$, respectively. Among the 359 patients, 51.0\% (176) and $49.0 \%$ (183) showed only unilateral right and left eye involvement, respectively, and no one showed bilateral involvement.

\section{Causative organisms}

Following the onset of endophthalmitis, 316 patients (88.0\%) underwent diagnostic tapping of ocular specimens for microbiological investigations, including vitreous and/or aqueous tap. All 316 diagnostic taps were performed at the time of initial presentation of ocular symptoms and prior to commencement of intravitreal antimicrobial therapy. The incidences of negative and positive cultures were 55.4 , and $44.6 \%$, respectively. Gram-positive organisms, Gram-negative organisms, mixed bacterial populations, and fungi were found to be the causative factors in 115 (81.6\%), 16 (11.3\%), four

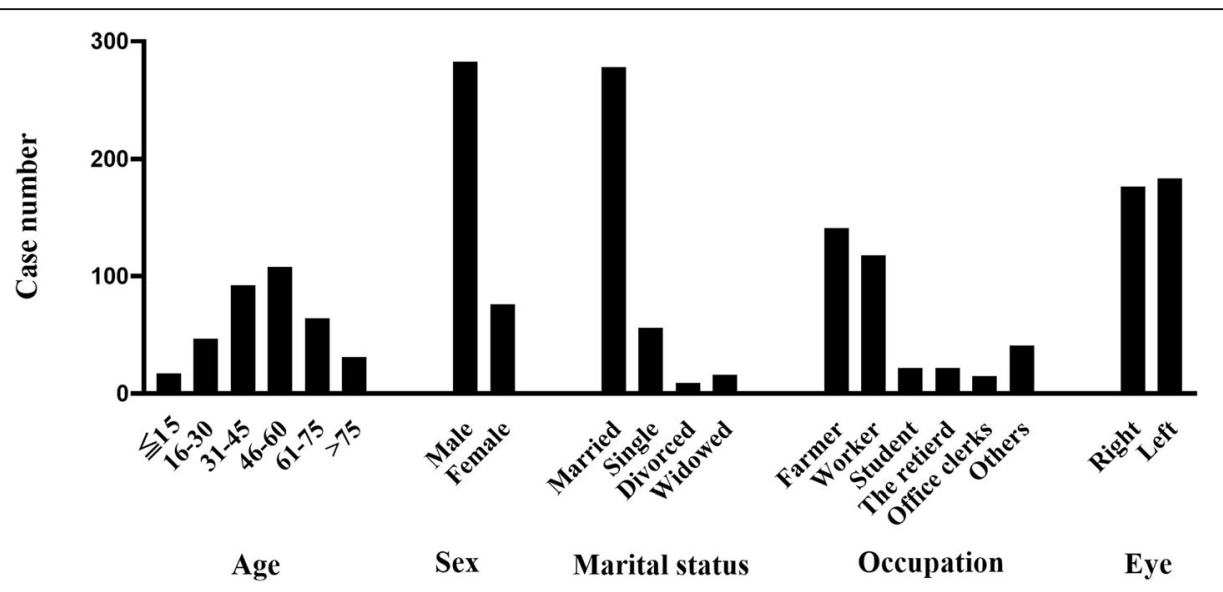

Fig. 1 Patient characteristics with infectious endophthalmitis in the Shanxi Eye Hospital, China from 2014 to 2018 
$(2.8 \%)$, and six eyes (4.3\%), respectively. As shown in Table 1, the most common microorganisms were Staphylococcus epidermidis (59 cases), followed by $S$. aureus (11 cases).

\section{Etiological classification}

Etiological classification of endophthalmitis was demonstrated (Table 2). Table 2 shows that ocular trauma, especially open globe injury, was the most frequent cause in our cases, accounting for $68.52 \%$ of all patients, Among the 246 posttraumatic cases, 87 (35.37\%) involved IOFB; 71 (28.86\%) and 16 (6.50\%) involving metals and non-metallic items, respectively. And 197 eyes $(80.08 \%)$ had zone I injuries, followed by zone II $(44,17.89 \%)$ and zone III (5, 2.03\%). Post-surgical endophthalmitis was the second most common cause, accounting for $22.6 \%$, and included post-cataract (62.96\%), post-glaucoma $(24.69 \%)$, post-PPV (11.11\%), and postIVI (1.23\%). Other causes were corneal ulcer-associated (CA) $(6.69 \%)$ and endogenous (2.22\%).

Statistical analysis of the factors among the four groups is shown in Table 2. There was no significant difference per year and affected eyes among the four

Table 1 Causative organisms in the 316 eyes with endophthalmitis

\begin{tabular}{|c|c|c|c|}
\hline Causative organisms & n (316) & Rate (\%) & Positive rate (\%) \\
\hline Culture-positive & 141 & $44.62 \%$ & $100.00 \%$ \\
\hline Gram-positive & 115 & $36.39 \%$ & $81.56 \%$ \\
\hline S. epidermidis & 59 & $18.67 \%$ & $41.84 \%$ \\
\hline S. aureus & 11 & $3.48 \%$ & $7.80 \%$ \\
\hline V. Streptococci & 9 & $2.85 \%$ & $6.38 \%$ \\
\hline S. pneumoniae & 7 & $2.22 \%$ & $4.96 \%$ \\
\hline Enterococcus & 7 & $2.22 \%$ & $4.96 \%$ \\
\hline S. mutans & 4 & $1.27 \%$ & $2.84 \%$ \\
\hline T. Streptococcus & 3 & $0.95 \%$ & $2.13 \%$ \\
\hline Micrococcus luteus & 3 & $0.95 \%$ & $2.13 \%$ \\
\hline Bacillus spp. & 4 & $1.27 \%$ & $2.84 \%$ \\
\hline Corynebacterium & 2 & $0.63 \%$ & $1.42 \%$ \\
\hline others & 6 & $1.90 \%$ & $4.26 \%$ \\
\hline Gram-negative & 16 & $5.06 \%$ & $11.35 \%$ \\
\hline Sphingomonas & 4 & $1.27 \%$ & $2.84 \%$ \\
\hline K. pneumoniae & 2 & $0.63 \%$ & $1.42 \%$ \\
\hline P. aeruginosa & 2 & $0.63 \%$ & $1.42 \%$ \\
\hline Dry Neisseria & 2 & $0.63 \%$ & $1.42 \%$ \\
\hline S. maltophilia & 2 & $0.63 \%$ & $1.42 \%$ \\
\hline others & 4 & $1.27 \%$ & $2.84 \%$ \\
\hline Mixed bacteria & 4 & $1.27 \%$ & $2.84 \%$ \\
\hline fungus & 6 & $1.90 \%$ & $4.26 \%$ \\
\hline Culture-negative & 175 & $55.38 \%$ & \\
\hline
\end{tabular}

groups ( $x^{2}$ test: $\left.P>0.05\right)$, but patients with endogenous endophthalmitis are more susceptible to the left eye. Age demonstrated a significant difference among the four groups $(\mathrm{F}=43.04, P<0.001)$, while the posttraumatic (41.67 \pm 15.51 years) and the endogenous $(67.13 \pm$ 16.13 years) groups had the lowest and highest age, respectively. There were significantly more men $(89.02 \%$, $P<0.05)$ in the posttraumatic group compared with the other groups, while the corneal ulcer-associated endophthalmitis tended to affect more women $(75.0 \%)\left(\chi^{2}=\right.$ $84.69, P<0.001)$. There was a significant difference in occupation distribution among the four groups, and the posttraumatic group tended to have more workers (43.90\%), while the other groups tended to have more farmers $(38.27,66.67$, and $50.00 \%$, respectively, $P<$ $0.001)$. The patient visit time significantly differed among the groups $\left(x^{2}=47.41, P<0.0001\right)$. Regarding therapy modalities, PPV was the most commonly performed in cases of posttraumatic and postsurgical endophthalmitis, while enucleation accounted for the most in corneal ulcer-associated and endogenous endophthalmitis cases $\left(X^{2}=137.3, P<0.0001\right)$. The causative organisms presented a significant difference among the four groups $\left(X^{2}=40.20, P=0.0004\right)$. The most cases of endogenous endophthalmitis tended to be caused by Gram-positive organisms (100\%), while fungus was the major cause in the corneal ulcer-associated group (42.86\%). The pre-therapy and post-therapy visual outcome were significantly different among the four groups $(\mathrm{F}=7.198, \mathrm{~F}=15.82$, respectively, $P<0.0001)$. The VAs improved and not improved in $120(33.52 \%)$ and 238 $(66.48 \%)$ cases. The improvement rate of VA was the highest in cases of postsurgical endophthalmitis $(81.48 \%)$, while the VAs were not significantly improved in cases of corneal ulcer-associated $(79.17 \%)$ and endogenous $(75.00 \%)$ endophthalmitis.

\section{Therapy modalities}

The therapy modalities are listed in Table 3. MT, defined as appropriate, topical, periocular, and systemic antibiotic administration, was used in 26 (7.24\%) cases. Combined vitrectomy and intraocular antibiotics were used in 243 (67.69\%) cases, whereas 54 (15.04\%) cases were treated with intravitreal antibiotic injections (IVA) alone, including vancomycin and ceftazidime. Enucleation was performed in 36 cases (10.03\%), 10 of which had their eyes removed in a second operation. Corneal ulcer-associated endophthalmitis was the most frequent cause in the enucleation group (Table 2).

\section{Visual outcome}

Visual outcomes were assessed for 358 eyes, excluding the eye of one child who did not cooperate during the vision test. The average logMAR BCVA value pre- 
Table 2 The etiological classification of infectious endophthalmitis

\begin{tabular}{|c|c|c|c|c|c|c|}
\hline \multirow[t]{2}{*}{ Variables } & Posttraumatic & Postsurgical & Corneal ulcer-associated & Endogenous & \multirow[t]{2}{*}{ Statistics } & \multirow[t]{2}{*}{$P$} \\
\hline & $246(68.52 \%)$ & $81(22.56 \%)$ & $24(6.69 \%)$ & $8(2.22 \%)$ & & \\
\hline \multicolumn{7}{|l|}{ Year } \\
\hline 2014 & $44(17.89 \%)$ & $16(19.75 \%)$ & $1(4.17 \%)$ & $1(12.50 \%)$ & \multirow[t]{5}{*}{$x^{2}=10.28$} & \multirow[t]{5}{*}{0.592} \\
\hline 2015 & $58(23.58 \%)$ & $14(17.28 \%)$ & $3(12.50 \%)$ & $1(12.50 \%)$ & & \\
\hline 2016 & $47(19.11 \%)$ & $19(23.46 \%)$ & $6(25.00 \%)$ & $1(12.50 \%)$ & & \\
\hline 2017 & 45 (18.29\%) & $16(19.75 \%)$ & $5(20.83 \%)$ & $2(25.00 \%)$ & & \\
\hline 2018 & $52(21.14 \%)$ & $16(19.75 \%)$ & $9(37.50 \%)$ & $3(37.50 \%)$ & & \\
\hline Age & $41.67 \pm 15.51$ & $62.21 \pm 17.17$ & $58.67 \pm 11.94$ & $67.13 \pm 16.13$ & $F=43.04$ & $<0.0001$ \\
\hline$\leqq 15$ & $15(6.10 \%)$ & $2(2.47 \%)$ & $0(0.00 \%)$ & $0(0.00 \%)$ & $x^{2}=134.5$ & $<0.0001$ \\
\hline $16-30$ & $42(17.07 \%)$ & $5(6.17 \%)$ & $0(0.00 \%)$ & $0(0.00 \%)$ & & \\
\hline $31-45$ & $84(34.15 \%)$ & $3(3.70 \%)$ & $4(16.67 \%)$ & $1(12.50 \%)$ & & \\
\hline $46-60$ & $80(32.52 \%)$ & 17 (20.99\%) & $9(37.50 \%)$ & $2(25.00 \%)$ & & \\
\hline $61-75$ & $20(8.13 \%)$ & $33(40.74 \%)$ & $10(41.67 \%)$ & $2(25.00 \%)$ & & \\
\hline$>75$ & $5(2.03 \%)$ & $21(25.93 \%)$ & $1(4.17 \%)$ & $3(37.50 \%)$ & & \\
\hline \multicolumn{7}{|l|}{ Sex } \\
\hline Male & 219 (89.02\%) & $42(51.85 \%)$ & $6(25.00 \%)$ & $4(50.00 \%)$ & \multirow[t]{2}{*}{$x^{2}=84.69$} & \multirow[t]{2}{*}{$<0.0001$} \\
\hline Female & 27 (10.98\%) & 39 (48.15\%) & $18(75.00 \%)$ & $4(50.00 \%)$ & & \\
\hline \multicolumn{7}{|l|}{ Occupation } \\
\hline Farmer & 90 (36.59\%) & 31 (38.27\%) & $16(66.67 \%)$ & $4(50.00 \%)$ & \multirow[t]{6}{*}{$x^{2}=102.7$} & \multirow[t]{6}{*}{$<0.0001$} \\
\hline Worker & 108 (43.90\%) & $9(11.11 \%)$ & $1(4.17 \%)$ & $0(0.00 \%)$ & & \\
\hline Student & $20(8.13 \%)$ & $2(2.47 \%)$ & $0(0.00 \%)$ & $0(0.00 \%)$ & & \\
\hline The retired & $1(0.41 \%)$ & 16 (19.75\%) & $4(16.67 \%)$ & $1(12.50 \%)$ & & \\
\hline Office clerks & $10(4.07 \%)$ & 4 (4.94\%) & $1(4.17 \%)$ & $0(0.00 \%)$ & & \\
\hline Others & 17 (6.91\%) & 19 (23.46\%) & $2(8.33 \%)$ & $3(37.50 \%)$ & & \\
\hline \multicolumn{7}{|l|}{ Eye } \\
\hline Right & 131 (53.25\%) & 48 (59.26\%) & 12 (50.00\%) & $1(12.50 \%)$ & \multirow[t]{2}{*}{$x^{2}=6.61$} & \multirow[t]{2}{*}{0.085} \\
\hline Left & 115 (46.75\%) & 33 (40.74\%) & 12 (50.00\%) & 7 (87.50\%) & & \\
\hline \multicolumn{7}{|l|}{ Visit time } \\
\hline$\leqq 7 d$ & 209 (84.96\%) & $60(74.07 \%)$ & $6(25.00 \%)$ & $6(75.00 \%)$ & \multirow[t]{2}{*}{$x^{2}=47.41$} & \multirow[t]{2}{*}{$<0.0001$} \\
\hline$>7 d$ & 37 (15.04\%) & 21 (25.93\%) & 18 (75.00\%) & $2(25.00 \%)$ & & \\
\hline \multicolumn{7}{|l|}{ Therapy } \\
\hline MT & $13(5.28 \%)$ & $9(11.11 \%)$ & $3(12.50 \%)$ & $1(12.50 \%)$ & \multirow[t]{5}{*}{$x^{2}=137.3$} & \multirow[t]{5}{*}{$<0.0001$} \\
\hline MT + IVA & 36 (14.63\%) & 14 (17.28\%) & $2(8.33 \%)$ & 2 (25.00\%) & & \\
\hline $\mathrm{MT}+\mathrm{IVA}+\mathrm{PPV}$ & $186(75.61 \%)$ & $53(65.43 \%)$ & $1(4.17 \%)$ & $2(25.00 \%)$ & & \\
\hline Enucleation & 11 (4.47\%) & $5(6.17 \%)$ & $18(75.00 \%)$ & $3(37.50 \%)$ & & \\
\hline COculture $(+)^{*}$ & 90 (40.72\%) & 40 (54.05\%) & 7 (58.33) & $4(50.00 \%)$ & & \\
\hline G+ bacteria & 74 (82.22\%) & $33(82.5 \%)$ & $4(57.14 \%)$ & $4(100.00 \%)$ & \multirow[t]{4}{*}{$x^{2}=40.42$} & \multirow[t]{4}{*}{0.0004} \\
\hline G- bacteria & $9(10.00 \%)$ & 7 (17.5\%) & $0(0.00 \%)$ & $0(0.00 \%)$ & & \\
\hline Mixed bacteria & $4(4.44 \%)$ & $0(0.00 \%)$ & $0(0.00 \%)$ & $0(0.00 \%)$ & & \\
\hline Fungus & $3(3.33 \%)$ & $0(0.00 \%)$ & $3(42.86 \%)$ & $0(0.00 \%)$ & & \\
\hline VA & & & & & & \\
\hline pre-therapy & $2.22 \pm 0.63$ & $2.30 \pm 0.52$ & $2.80 \pm 0.35$ & $2.44 \pm 0.70$ & $F=7.198$ & $<0.0001$ \\
\hline$\leqq 2.3$ & 195 (79.27\%) & $68(83.95 \%)$ & $22(91.67 \%)$ & 7 (87.50\%) & $x^{2}=3.307$ & 0.3467 \\
\hline$>2.3$ & $51(20.73 \%)$ & $12(14.81 \%)$ & $2(8.33 \%)$ & $1(12.50 \%)$ & & \\
\hline
\end{tabular}


Table 2 The etiological classification of infectious endophthalmitis (Continued)

\begin{tabular}{|c|c|c|c|c|c|c|}
\hline \multirow[t]{2}{*}{ Variables } & Posttraumatic & Postsurgical & Corneal ulcer-associated & Endogenous & \multirow[t]{2}{*}{ Statistics } & \multirow[t]{2}{*}{$P$} \\
\hline & $246(68.52 \%)$ & $81(22.56 \%)$ & $24(6.69 \%)$ & $8(2.22 \%)$ & & \\
\hline post- therapy & $1.59 \pm 0.80$ & $1.53 \pm 0.76$ & $2.64 \pm 0.69$ & $2.34 \pm 0.87$ & $F=15.82$ & $<0.0001$ \\
\hline$\leqq 2.3$ & 78 (31.71\%) & $21(25.93 \%)$ & $19(79.17 \%)$ & $6(75.00 \%)$ & $x^{2}=30.2$ & $<0.0001$ \\
\hline$>2.3$ & $168(68.29 \%)$ & $59(72.84 \%)$ & $5(20.83 \%)$ & $2(25.00 \%)$ & & \\
\hline \multicolumn{7}{|l|}{ VA improved } \\
\hline Not improved & 80 (32.52\%) & $15(18.52 \%)$ & $19(79.17 \%)$ & $6(75.00 \%)$ & $x^{2}=36.96$ & $<0.0001$ \\
\hline Improved & $166(67.48 \%)$ & $66(81.48 \%)$ & $5(20.83 \%)$ & $2(25.00 \%)$ & & \\
\hline \multicolumn{7}{|c|}{ Wound location** } \\
\hline Zone I & 197 (80.08\%) & - & - & - & & \\
\hline Zone II & $44(17.89 \%)$ & - & - & - & & \\
\hline Zone III & $5(2.03 \%)$ & - & - & - & & \\
\hline \multicolumn{7}{|l|}{$\mathrm{IOFB}^{* *}$} \\
\hline NO & $159(64.63 \%)$ & - & - & - & & \\
\hline Metal & $69(28.05 \%)$ & - & - & - & & \\
\hline Non-metal & $18(7.32 \%)$ & - & - & - & & \\
\hline
\end{tabular}

*141 cases of causative organisms positive cultures were included in statistics analysis

**246 cases of posttraumatic endophthalmitis were included in statistics analysis

CO Causative organisms, IOFB intraocular foreign body, PPV pars plana vitrectomy, IVI intravitreal injection, MT medical therapy, IVA intravitreal antibiotic

injections, $V A$ visual acuity, G+ gram-positive, G- gram-negative

therapy was $2.28 \pm 0.60$ and significantly improved to $1.67 \pm 0.83$ at post-therapy $(\mathrm{t}=7.161, P<0.0001)$.

Pre-therapy and post-therapy VAs were compared among the four groups (Gram-positive, Gram-negative, fungi, and culture-negative) are shown in Fig. 2a. We observed a significant difference in VA between Grampositive $(\mathrm{G}+)$ and culture-negative patients at pretherapy and post-therapy $(P<0.0001)$, while there was no significant difference in patients with Gram-negative (G-) bacterial and fungal infection. Figure $2 b$ showed the statistical difference between pre-therapy and posttherapy in MT, MT + IVA, and MT + IVA + PPV $(P<$ $0.0001)$, while the post-therapy VA values were not significantly different in these therapy modalities.

Demographic and clinical features associated with improved VA are demonstrated in Table 4. There were no significant differences in average age, but there were in the segment of age and sex $(P<0.05)$. For eye and

Table 3 Therapy modalities

\begin{tabular}{lll}
\hline Therapy modalities & $n$ & Rate (\%) \\
\hline 1 MT & 26 & $7.24 \%$ \\
2 MT + IVA & 54 & $15.04 \%$ \\
3 MT + IVA + PPV & 243 & $67.69 \%$ \\
4 Enucleation & 36 & $10.03 \%$ \\
Total & 359 & $100.0 \%$ \\
\hline
\end{tabular}

MT medical therapy, IVA intravitreal antibiotic injections, PPV pars plana vitrectomy occupation, there were no statistically significant differences $(P>0.05)$. The average visit time and time segment were statistically different in the not-improved and improved groups. It was noted that post-traumatic and post-surgical endophthalmitis had obvious improved visual outcomes compared to those having other types of endophthalmitis, and the difference was statistically significant $\left(X^{2}=41.98, P<0.0001\right)$. For causative organisms, in 141 cases of positive cultures, G+ coccus showed the most favorable visual outcomes when compared to others, presenting statistically significant differences $\left(X^{2}=12.93, P=0.0047\right)$. Regarding therapy modalities, PPV led to significantly improved visual outcomes $\left(X^{2}=\right.$ 87.15, $P<0.0001$ ), and the pre-therapy VA displayed an important role in improving vision, especially the patient's VA $\leqq \operatorname{logMAR} 2.3$ showed a trend of statistically significant improvement $\left(X^{2}=9.00, P=0.003\right)$. Among 246 patients with post-traumatic endophthalmitis, the presence of IOFB $\left(X^{2}=4.841, P<0.0001\right)$ and the wound location $\left(x^{2}=7.398, P=0.0247\right)$ were significantly correlated with improved VA. However, there was no significant difference between metal and non-metal IOFB. The visual improvement in zone I was significantly better than that in zone II and III.

\section{Binomial logistic regression analysis of predictive factors of improved VA}

Multivariate analysis using a binomial logistic regression model was conducted to examine the predictive factors 


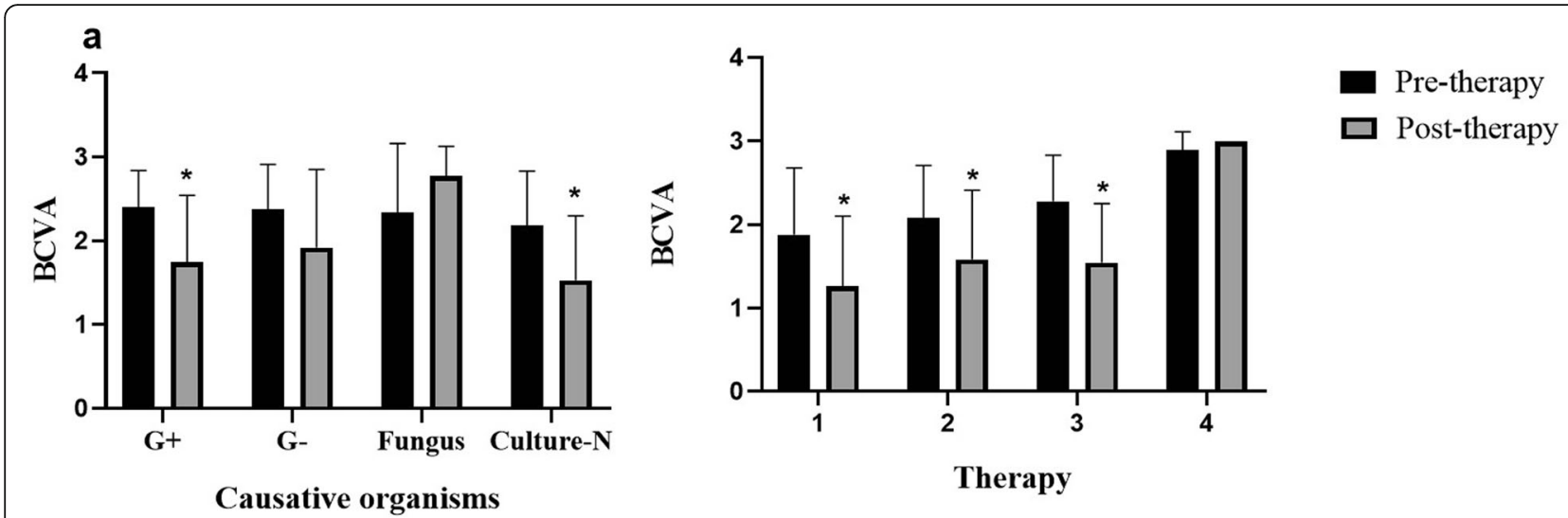

Fig. 2 Comparison of pre- and post-therapy BCVA between difference causative bacteria $\mathbf{a}$ and therapy modalities $\mathbf{b}$ *Using analysis of variance (ANOVA), P-value between pre-therapy BCVA and post-therapy BCVA P<0.05. (1:MT, 2. MT + IVA. 3:MT + IVA + PPV. 4: Enucleation)

of improved VA. After adjusting for possible confounding factors, visit time $>7$ day $(P=0.034, \mathrm{OR}=0.522$, 95\%CI: 0.286-0.953), pre-therapy VA $\leqq \log M A R 2.3(P=$ 0.032, OR $=1.809,95 \% \mathrm{CI}: 1.052-3.110)$, etiology of PS (vs. PT; $P=0.023, \mathrm{OR}=2.100,95 \% \mathrm{CI}: 1.109-3.974$ ) and etiology of CA (vs. PT; $P=0.005, \mathrm{OR}=0.202,95 \% \mathrm{CI}$ : $0.066-0.621)$ were significantly associated with improved VA (Table 4).

\section{Discussion}

In our retrospective study, the average age of patients was $48.01 \pm 18.27$ years, and the patients were mostly young and middle-aged, resulting in a significant impact on their families and our society. Interestingly, the average age of patients with endophthalmitis in Germany was $69.3 \pm 1.7$ years [14], while the corresponding in western China was $35.1 \pm 20.3$ years [2]. There were significant differences in sex distribution among the patients with endophthalmitis between the developed and developing countries. In developed countries, the distribution in men and women was almost the balance [3], but in India [16] and China (the western region) [2], the proportion in men was significantly higher than in women, which is consistent with our result. The latter could be explained as women are rarely engaged in physical activity, which results in less ocular trauma. In our study, the patients were farmers (39.3\%), workers (32.9\%), office clerks (4.2\%), retirees $(6.1 \%)$, students (16.1\%), and others $(11.4 \%)$. The highest proportion of patients consisted of farmers and workers, which was similar to the epidemiological characteristics in other countries $[2,14,17]$. This may be related to the fact that workers and farmers are more prone to trauma and the high-risk nature of their occupations. For injured eyes, there is no statistical difference between the left and right eyes in general.
The results obtained for pathogenic bacteria were consistent with the findings of most reports [2, 14, 18, 19]. We obtained anterior aqueous humor and or vitreous fluid for bacterial culture from 316 patients, and the culture-positive rate was $44.62 \%$. Among the culturepositive cases, Gram-positive bacteria, Gram-negative bacteria, fungi, and mixed bacterial infections accounted for $81.6,11.3,4.3$, and $2.8 \%$ of the cases. S.epidermidis was the highest rate in the common pathogens, which was similar with that in Thailand [18]. In contrast, $S$. aureus is more common in other countries [14, 20]. The causative organisms are highly correlated with VA [21]. In terms of the relationship between bacteria and VA, there was a significant difference in the visual acuity between pre-therapy and post-therapy in the Grampositive and culture-negative groups, but there was no significant difference in the Gram-negative and fungal infection groups, which may be related to the highly virulent and the rapid infection progress of Gramnegative bacteria and the poor therapeutic effect in these cases [12]. Thus, the pathogenicity of the microorganisms significantly influenced the prognosis.

The etiology of the disease was categorized into four groups: posttraumatic, postoperative, corneal ulcerrelated, and endogenous [22]. We analyzed the various factors' differences among the four groups. In our study, posttraumatic endophthalmitis was the main cause, accounting for $68.52 \%$, followed by postoperative complications (22.56\%). Similarly, a German report showed that endogenous endophthalmitis accounted for $41 \%$ of the cases [9]. In contrast, a study conducted in Odisha, India, reported that $43.0 \%$ of the cases had a postoperative etiology while $40.2 \%$ were post-traumatic [16], while one study performed in the western region of China reported that $82.6 \%$ of 1593 endophthalmitis cases were posttraumatic. In the posttraumatic group, the patients 
Table 4 Patient demographic characteristics of multivariable logistic regression analysis of the factors associated with improved visual acuity in 358 cases

\begin{tabular}{|c|c|c|c|c|c|c|}
\hline \multirow[t]{2}{*}{ Factors } & \multirow{2}{*}{$\begin{array}{l}\text { Not improved } \\
\text { (120) }\end{array}$} & \multirow{2}{*}{$\begin{array}{l}\text { Improved } \\
(238)\end{array}$} & \multirow[t]{2}{*}{$t / x^{2}$} & \multirow[t]{2}{*}{$P$} & \multicolumn{2}{|l|}{ Multivariable analysis } \\
\hline & & & & & OR(95\%Cl) & $P$ \\
\hline Age & $47.33 \pm 17.65$ & $48.54 \pm 18.41$ & $t=0.595$ & 0.552 & & \\
\hline $0-15$ & $1(0.83 \%)$ & 15 (6.30\%) & $x^{2}=14.30$ & 0.014 & 0.00 (Reference) & \\
\hline $16-30$ & $24(20.00 \%)$ & $23(9.66 \%)$ & & & $0.462(0.110-1.950)$ & 0.293 \\
\hline $31-45$ & $31(25.83 \%)$ & $61(25.63 \%)$ & & & $0.434(0.110-1.726)$ & 0.234 \\
\hline $46-60$ & $31(25.83 \%)$ & 77 (32.35\%) & & & $0.557(0.143-2.169)$ & 0.399 \\
\hline $61-75$ & $25(20.83 \%)$ & $40(16.81 \%)$ & & & $0.742(0.181-3.034)$ & 0.678 \\
\hline$>75$ & $8(6.67 \%)$ & $22(9.24 \%)$ & & & $0.400(0.088-1.813)$ & 0.235 \\
\hline \multicolumn{7}{|l|}{ Sex } \\
\hline Male & 102 (85.00\%) & $180(75.63 \%)$ & $x^{2}=4.188$ & 0.041 & 0.00 (Reference) & \\
\hline Female & $18(15.00 \%)$ & $58(24.37 \%)$ & & & $1.387(0.719-2.675)$ & 0.329 \\
\hline \multicolumn{7}{|l|}{ Occupation } \\
\hline Farmer & $50(41.67 \%)$ & 91 (38.24\%) & $x^{2}=3.825$ & 0.575 & - & \\
\hline Worker & $40(33.33 \%)$ & $78(32.77 \%)$ & & & & \\
\hline Student & $4(3.33 \%)$ & 17 (7.14\%) & & & & \\
\hline The retired & $5(4.17 \%)$ & $17(7.14 \%)$ & & & & \\
\hline Office clerks & $6(5.00 \%)$ & $9(3.78 \%)$ & & & & \\
\hline Others & $15(12.50 \%)$ & $26(10.92 \%)$ & & & & \\
\hline \multicolumn{7}{|l|}{ Eye } \\
\hline Right & $58(48.33 \%)$ & 118 (49.58\%) & $x^{2}=0.0496$ & 0.824 & - & \\
\hline Left & $62(51.67 \%)$ & $120(50.42 \%)$ & & & & \\
\hline Visit time & $8.86 \pm 13.33$ & $5.68 \pm 9.10$ & $t=2.654$ & 0.0083 & & \\
\hline$\leqq 7 D$ & 85 (70.83\%) & 194 (81.51\%) & $x^{2}=5.290$ & 0.0214 & 0.00 (Reference) & \\
\hline$>7 D$ & 35 (29.17\%) & 44 (18.49\%) & & & $0.522(0.286-0.953)$ & 0.034 \\
\hline \multicolumn{7}{|l|}{ EC } \\
\hline PT & $80(66.67 \%)$ & $166(69.75 \%)$ & $x^{2}=41.98$ & $<0.0001$ & 0.00 (Reference) & \\
\hline PS & $15(12.50 \%)$ & 65 (27.31\%) & & & $2.100(1.109-3.974)$ & 0.023 \\
\hline$C A$ & 19 (15.83\%) & $5(2.10 \%)$ & & & $0.202(0.066-0.621)$ & 0.005 \\
\hline Ed & $6(5.00 \%)$ & $2(0.84 \%)$ & & & $0.194(0.286-0.953)$ & 0.053 \\
\hline Pre-therapy VA & $2.28 \pm 0.60$ & $1.67 \pm 0.83$ & $t=7.161$ & $<0.0001$ & & \\
\hline$>\log M A R 2.3$ & $60(50.00 \%)$ & 79 (33.19\%) & $x^{2}=9.00$ & 0.003 & 0.00 (Reference) & \\
\hline$\leqq \operatorname{logMAR2.3}$ & $60(50.00 \%)$ & 159 (66.81\%) & & & $1.809(1.052-3.100)$ & 0.032 \\
\hline \multicolumn{7}{|l|}{ TM } \\
\hline MD & $4(3.33 \%)$ & 22 (9.24\%) & $x^{2}=87.15$ & $<0.0001$ & & \\
\hline$M D+I V I$ & $23(19.17 \%)$ & $31(13.03 \%)$ & & & & \\
\hline$M D+I V I+P P V$ & $57(47.50 \%)$ & 185 (77.73\%) & & & & \\
\hline Enucleation & $36(30.00 \%)$ & $0(0.00 \%)$ & & & & \\
\hline CO Culture $(+)^{*}$ & 49 & 92 & & & - & \\
\hline G+ bacteria & $35(71.43 \%)$ & $80(88.24 \%)$ & $x^{2}=12.93$ & 0.0047 & & \\
\hline G- bacteria & 7 (14.29\%) & $9(8.24 \%)$ & & & & \\
\hline Mixed bacteria & $1(2.04 \%)$ & $3(3.53 \%)$ & & & & \\
\hline fungus & $6(12.24 \%)$ & $0(0.00 \%)$ & & & & \\
\hline
\end{tabular}


Table 4 Patient demographic characteristics of multivariable logistic regression analysis of the factors associated with improved visual acuity in 358 cases (Continued)

\begin{tabular}{|c|c|c|c|c|c|c|}
\hline \multirow[t]{2}{*}{ Factors } & \multirow{2}{*}{$\begin{array}{l}\text { Not improved } \\
\text { (120) }\end{array}$} & \multirow{2}{*}{$\begin{array}{l}\text { Improved } \\
(238)\end{array}$} & \multirow[t]{2}{*}{$t / x^{2}$} & \multirow[t]{2}{*}{$P$} & \multicolumn{2}{|c|}{ Multivariable analysis } \\
\hline & & & & & OR(95\%Cl) & $P$ \\
\hline No & $44(55.00 \%)$ & 115 (69.28\%) & $x^{2}=4.814$ & 0.0282 & & \\
\hline Yes & $36(45.00 \%)$ & $51(30.72 \%)$ & & & & \\
\hline Metal & $27(75.00 \%)$ & $44(86.27 \%)$ & $x^{2}=1.787$ & 0.1812 & & \\
\hline Non-metal & 9 (25.00\%) & 7 (13.73\%) & & & & \\
\hline Wound location* & 80 & 166 & $x^{2}=7.398$ & 0.0247 & - & \\
\hline Zone I & $58(72.50 \%)$ & 139 (83.73\%) & & & & \\
\hline Zone II & $18(22.50 \%)$ & $26(15.66 \%)$ & & & & \\
\hline Zone III & 4 (5.00\%) & 1 (0.60\%) & & & & \\
\hline
\end{tabular}

*246 cases of posttraumatic endophthalmitis were included in the $x^{2}$ test, but not in the Logistic regression analysis

** 141 cases of positive causative organism's cultures were included in the in the $x^{2}$ test, but not the Logistic regression analysis

TM Therapy modalities, EC Etiological classification, CO Causative organisms, OR Odds ratio, PT Post-traumatic, PS Post-surgical, CA Corneal ulcer-associated,

Ed Endogenous

were significantly younger with an average age of $41.67 \pm 15.51$ years. The average $\log$ MAR BCVA significantly improved from $2.22 \pm 0.63$ on pre-therapy to $1.59 \pm 0.80$ on post-therapy $(P<0.0001)$, the VA improvement rate reached $67.48 \%$, which might be related to PPV, the main therapy modality. Regarding the pathogenic bacteria, the Gram-positive bacteria were the most common and even multiple mixed infections existed [23]. Wound location was dominated by zone I, and 87 cases $(35.4 \%)$ were complicated with intraocular foreign bodies, including $71(28.5 \%)$ and $16(6.5 \%)$ cases of metallic and non-metallic foreign bodies, respectively, in line with findings from other regions [23, 24]. Regarding the postoperative group, the proportion of retirees and the age increased significantly, with an average age of $62.21 \pm 17.17$ years, and there was no significant difference in the male to female ratio, and the VA improvement rate $(81.48 \%)$ was the most significant among the four groups, while the treatment was also dominated by PPV. However, in the corneal ulcer-related endophthalmitis group, the proportion of women was the highest among the groups, and the pathogenic bacteria were $\mathrm{G}+$ bacteria and fungi; because of the delayed visit time and the poor pre-therapy VA, the proportion of enucleation was the highest in the four types. In endogenous endophthalmitis, which was caused by hematogenous spread, we did not only find that the average age was the oldest and the pathogenic bacteria were all G+ bacteria, which was consistent with previous reports $[7,21]$; interestingly, the left eye was most involved, and there was the statistical difference compared with the posttraumatic and postoperative groups. This finding was inconsistent with the previous findings that reported greater involvement of the right eye than of the left eye $[3,25]$. We hypothesized that a bacterial embolus is more likely to enter the left carotid artery and flow into the terminal artery, the central retinal artery of the left eye, considering the anatomy character, the right common carotid originates in the neck from the brachiocephalic trunk, while the left directly arises from the aortic arch. Nevertheless, this result may not be convincing, due to the small sample sizes and the limitations of ophthalmology hospitals. Different etiology, different VA prognosis results, and corneal ulcer-related endophthalmitis had the worst postoperative VA $(2.64 \pm 0.69)$. The posttraumatic and postoperative groups presented significantly improved VAs, while corneal ulcer-related and endogenous endophthalmitis had a higher rate of unimproved VA, with statistically significant differences.

All 359 patients received topical and intravenous antibiotics, including vancomycin alone or ceftazidime in combination. All patients did not receive intraocular antibiotics before onset; however, some patients underwent systemic antibiotic administration [23]. There are different therapeutic modalities for infectious endophthalmitis according to the severity. According to our data analysis, there was a relationship between different therapy and vision improvement. According to Fig. 2 and Table 4, in addition to enucleation, the improvement of VA was statistically significant in various treatment methods, while in the PPV group this improvement was significantly higher than in the other groups, which was similar to the results of other researches $[4,6]$. Therefore, PPV is considered the main therapy strategy in cases of infectious endophthalmitis $[4,5,22]$.

The improved VA after treatment was considered the primary outcome, therefore we investigated various factors that may affect the improvement of VA, including age, sex, etiology, pre-therapy VA, patient visit time, pathogenic microorganisms, therapy modalities etc. In the posttraumatic endophthalmitis, the presence of IOFB and wound location were associated with improved 
vision, but the metal or non-metal relationship was not significant. The improvement in vision in zone III was significantly worse than in zone I and II. Finally, multivariate analysis using binomial logistic regression was performed on these factors with $P>0.05$, while the therapy modalities were an intermediate variable, affected by many factors, so they were not included in the regression study. We found that the patient visit time, pretherapy VA, and the etiology were important factors for visual improvement, and no correlation was found with age and pathogenic bacteria. The visual outcomes caused by different pathogenic bacteria were inconsistent, but no statistical difference was found in logistic regression analysis, which may be caused by a relatively lower bacterial positive culture rate, correlations with etiology, patient visit time, and visual outcome.

Nevertheless, this retrospective analysis had some limitations: (1) It had a single-center and retrospective design. A prospective, randomized study design would have been more desirable. (2) The Shanxi Eye Hospital is the largest ophthalmology hospital in Shanxi Province. However, patients with a severe systemic disease are referred to a general hospital; thus, we may not have obtained the data for a large number of patients with endogenous endophthalmitis, leading to sample bias. (3) In terms of VA, we did not perform final follow-up assessments, and we only assessed the vision at a single hospitalization and discharge, because traumatic cataract and postoperative inflammatory reaction would affect vision. In future studies, we intend to collect these data. Therefore, we will perform longer follow-up time studies in the future to observe more potential complications and final recover sight. Moreover, multiple imaging modalities (e.g., structural and functional) optical coherence tomography, fluorescein angiography, indocyanine green angiography, and autofluorescence can be included to find more quantitative parameters in patients diagnosed with infectious endophthalmitis.

\section{Conclusions}

In summary, our study revealed that the incidence of infectious endophthalmitis was much higher in farmers and workers of middle age population in Shanxi Province. Moreover, the final visual outcomes were related with types of endophthalmitis, and two additional factors, such as early treatment and good initial visual acuity, played an important role in the final visual recovery.

\footnotetext{
Abbreviations

BCVA: Best-corrected visual acuity; CA: Corneal ulcer-associated; CFs: Counting fingers; CO: Causative organisms; EC: Etiological classification; Ed: Endogenous; G-: Gram-negative; G + : Gram-positive; HM: Hand movement; IOFB: Intraocular foreign body; IVA: Intravitreal antibiotic injections; IVI: Intraocular injection; LP: Light perception; MT: Medical therapy; NLP: No LP; OR: Odds ratio; PPV: Pars plana vitrectomy; PS: Post-surgical; PT: Post-traumatic; TM: Therapy modalities; VA: Visual acuity
}

\section{Acknowledgements}

Not applicable.

\section{Authors' contributions}

HY and XMZ conceived and designed the study. ZG, YDZ, and XHG collected and reviewed the patient data. JJW, TM, and GYL analyzed the data and provided interpretation. ZG was the major contributor in writing the manuscript. All authors read and approved the final manuscript.

\section{Funding}

This is supported by the National Natural Science Foundation of China (Grant Numbers 81830026) and Natural Science Foundation of Tianjin (Grant Number 18ZXDBSY00030). Data Analysis and Collection were supported by the Dr. HUA Y AN's funding.

\section{Availability of data and materials}

The analytical data in this study could be obtained from the corresponding author upon reasonable request.

\section{Ethics approval and consent to participate}

This study was in accordance with the tenets of the Helsinki Declaration and was approved by the Shanxi Eye Hospital Ethics Committee. The requirement for informed consent was waived due to the retrospective nature of this study.

\section{Consent for publication}

Not applicable.

\section{Competing interests}

The authors declare no conflict of interest.

\section{Author details}

${ }^{1}$ Department of Ophthalmfology, Tianjin Medical University General Hospital, No. 154, Anshan Road, Tianjin 300052, China. ${ }^{2}$ Department of Vitreoretinopathy, Shanxi Eye Hospital, Taiyuan 030001, Shanxi, China. ${ }^{3}$ Department of Medical Services, Shanxi Eye Hospital, Taiyuan 030001, Shanxi, China.

Received: 3 April 2020 Accepted: 12 June 2020

Published online: 29 June 2020

\section{References}

1. Hassana J, MacGowana AP, Cook SD. Endophthalmitis at the Bristol eye hospital: an 11-year review of 47 patients. J Hosp Infect. 1992;22:271-8.

2. Yang XB, Liu YY, Huang ZX, Mao Y, Zhao L, Xu ZP. Clinical analysis of 1593 patients with infectious endophthalmitis: a 12-year study at a tertiary referral center in western China. Chin Med J (Engl). 2018;131:1658-65.

3. Sheu SJ. Endophthalmitis. Korean J Ophthalmol. 2017;31:283-9.

4. Sansome SG, Ting M, Jain S. Endophthalmitis. Br J Hosp Med (Lond). 2019; 80:C8-C11.

5. Durand ML. Endophthalmitis. Clin Microbiol. 2013;19:227-34.

6. Yospaiboon Y, Meethongkam K, Sinawat S, Laovirojjanakul W, Ratanapakorn T, Sanguansak T, Bhoomibunchoo C. Predictive factors in the treatment of streptococcal endophthalmitis. Clin Ophthalmol. 2018;12:859-64.

7. Ratra D, Saurabh K, Das D, Nachiappan K, Nagpal A, Rishi E, et al. Endogenous endophthalmitis: a 10-year retrospective study at a tertiary hospital in South India. Asia Pac J Ophthalmol (Phila). 2015;4:286-92.

8. Gounder PA, Hille DM, Khoo YJ, Phagura RS, Chen FK. ENDOGENOUS ENDOPHTHALMITIS IN WESTERN AUSTRALIA: A Sixteen-Year Retrospective Study. Retina (Philadelphia, Pa.). 2020 May;40(5):908-18.

9. Krause L, Bechrakis NE, Heimann H, Kildal D, Foerster MH. Incidence and outcome of endophthalmitis over a 13-year period. Can J Ophthalmol. 2009:44:88-94.

10. Lemley CA, Han DP. Endophthalmitis: a review of current evaluation and management. Retina (Philadelphia, Pa.). 2007;27:662-80.

11. Schulze-Bonsel K, Feltgen N, Burau H, Hansen L, Bach M. Visual acuities "hand motion" and "counting fingers" can be quantified with the freiburg visual acuity test. Invest Ophthalmol Vis Sci. 2006;47:1236-40.

12. Wu ZH, Chan RP, Luk FO, Liu DT, Chan CK, Lam DS, et al. Review of clinical features, microbiological spectrum, and treatment outcomes of 
endogenous endophthalmitis over an 8-year period. J Ophthalmol 2012; 2012:265078.

13. Forster RK. The endophthalmitis vitrectomy study. Arch Ophthalmol. 1995; 113:1555-7.

14. Kitsche M, Herber R, Pillunat LE, Terai N. Clinical and visual outcome of endophthalmitis patients: a single-center experience. Graefes Arch Clin Exp Ophthalmol. 2020;258:183-9.

15. Fliney GD, Pecen PE, Cathcart JN, Palestine AG. Trends in treatment strategies for suspected bacterial endophthalmitis, Graefe's Arch Clin Exp Ophthalmol. 2018;256:833-8.

16. Sharma S, Padhi TR, Basu S, Kar S, Roy A, Das T. Endophthalmitis patients seen in a tertiary eye care Centre in Odisha: a clinico-microbiological analysis. Indian J Med Res. 2014;139:91-8.

17. Durand ML. Bacterial and fungal endophthalmitis. Clin Microbiol Rev. 2017; 30:597-613.

18. Bhoomibunchoo C, Ratanapakorn T, Sinawat S, Sanguansak T, Moontawee K, Yospaiboon Y. Infectious endophthalmitis: review of 420 cases. Clin Ophthalmol. 2013;7:247-52

19. Yospaiboon $Y$, Intarapanich A, Laovirojjanakul W, Ratanapakorn T, Sinawat $S$, Sanguansak $T$, et al. Factors affecting visual outcomes after treatment of infectious endophthalmitis in northeastern Thailand. Clin Ophthalmol. 2018; 12:765-72.

20. Loukovaara S, Järventausta P, Anttila VJ. Pathogenic causes and outcomes of endophthalmitis after vitreoretinal surgeries in Finland from 2009 to 2018. Acta Ophthalmol. 2020;98(1):e128-30.

21. Gounder PA, Hille DM, Khoo YJ, Phagura RS, Chen FK. Endogenous endophthalmitis in Western Australia: a sixteen-year retrospective study. Retina. 2019;40:908-18.

22. Relhan N, Forster RK, Flynn HW. Endophthalmitis: Then and Now. Am J Ophthalmol. 2018;187:xx-xxvii.

23. Callegan MC, Gilmore MS, Gregory M, Ramadan RT, Wiskur BJ, Moyer AL, et al. Bacterial endophthalmitis: therapeutic challenges and host-pathogen interactions. Prog Retin Eye Res. 2007;26:189-203.

24. Meng Y, Yan H. Prognostic factors for open globe injuries and correlation of ocular trauma score in Tianjin, China. J Ophthalmol $2015 ; 2015: 345764$.

25. Greenwald MJ, Wohl LG, Sell CH. Metastatic bacterial endophthalmitis: a contemporary reappraisal. Surv Ophthalmol. 1986;31(2):81-101.

\section{Publisher's Note}

Springer Nature remains neutral with regard to jurisdictional claims in published maps and institutional affiliations.

Ready to submit your research? Choose BMC and benefit from:

- fast, convenient online submission

- thorough peer review by experienced researchers in your field

- rapid publication on acceptance

- support for research data, including large and complex data types

- gold Open Access which fosters wider collaboration and increased citations

- maximum visibility for your research: over $100 \mathrm{M}$ website views per year

At BMC, research is always in progress.

Learn more biomedcentral.com/submissions 